\title{
Perception of Indian Dental Surgeons regarding Molar Incisor Hypomineralization
}

\author{
${ }^{1}$ Sumita Upadhyay, ${ }^{2}$ Gyanendra Kumar, ${ }^{3}$ Jatinder K Dhillon, ${ }^{4}$ Namrata C Gill
}

\begin{abstract}
Aim: To determine the perception of Indian dental professionals about prevalence, severity, and etiological factors of molar incisor hypomineralization (MIH).

Materials and methods: An online survey was mailed to dental professionals encompassing various questions regarding etiology, diagnosis, prevalence, and management of $\mathrm{MIH}$.

Results: More than $90 \%$ of the respondents encounter teeth with hypomineralization in their practice, with less than half of them encountering such teeth on a monthly basis. Among these more than one-third find it difficult to manage one or the other aspect of MIH. The etiology was found to be varying as per the respondents.
\end{abstract}

Conclusion: Molar incisor hypomineralization is a common condition encountered by dental professionals with no apparent consensus regarding the anticipated prevalence, severity, and etiology of this condition. Knowledge of clinicians' level of perception could be an incentive for pediatric dentists to become more acquainted with $\mathrm{MIH}$ by conducting research into its different aspects.

Keywords: Dental surgeons, Molar incisor hypomineralization, Perception.

How to cite this article: Upadhyay S, Kumar G, Dhillon JK, Gill NC. Perception of Indian Dental Surgeons regarding Molar Incisor Hypomineralization. Int J Clin Pediatr Dent 2018;11(2):116-121.

Source of support: Nil

Conflict of interest: None

\section{INTRODUCTION}

Incisors and first permanent molars with severe hypomineralized enamel of unknown etiology were

\footnotetext{
1,3,4 Assistant Professor, ${ }^{2}$ Associate Professor

${ }^{1}$ Department of Pediatric Dentistry, Kathmandu University School of Medical Sciences, Dhulikhel Hospital, Dhulikhel, Nepal

${ }^{2,3}$ Department of Pedodontics and Preventive Dentistry, Maulana Azad Institute of Dental Sciences, New Delhi, India

${ }^{4}$ Department of Pedodontics and Preventive Dentistry Dr. Harvansh Singh Judge Institute of Dental Sciences \& Hospital, Panjab University, Chandigarh, India

Corresponding Author: Jatinder K Dhillon, Assistant Professor Department of Pedodontics and Preventive Dentistry, Maulana Azad Institute of Dental Sciences, New Delhi, India, e-mail: dr.jatinderdhillon@gmail.com
}

first acknowledged in Sweden in the late 1970s. ${ }^{1}$ This condition has been referred to as "idiopathic enamel hypomineralization in permanent first molars," "hypomineralized permanent first molars," "cheese molars," and "nonfluoride hypomineralization in permanent first molars."1-6 The term " MIH" was introduced by Weerheijm et al ${ }^{7}$ to describe this condition. Molar incisor hypomineralization is defined as hypomineralization of systemic origin of permanent first molars, frequently associated with affected incisors. One or more of the molars may be affected, each with different degrees of severity. The permanent incisors may also be affected. Even though MIH is defined as a chronological and general disturbance, the number of permanent first molars and the degree of hypomineralization vary extensively.

The clinical management of $\mathrm{MIH}$ is challenging for the dentist due to sensitivity and rapid development of dental caries in affected permanent first molars, difficulty in achieving anesthesia, unpredictable behavior of apparently intact opacities, and repeated marginal breakdown of restorations and difficulty in cavity preparation. ${ }^{8,9}$ This is due to enamel in teeth affected by MIH exhibiting disorganized enamel prisms, a porous structure, and loosely packed crystallites. ${ }^{10-14}$

The prevalence varies considerably from $2.8 \%$ in Hong Kong Chinese children ${ }^{15}$ to almost $40 \%$ in Denmark and Brazil. ${ }^{16,17}$ The reasons for this variation may be lack of consistent and standardized assessment criteria. There have been recent surveys among pediatric dentists in Europe ${ }^{18}$ Australia and New Zealand, ${ }^{19}$ and Iraq ${ }^{20}$ to ascertain the knowledge and practice regarding MIH. Such surveys aim to reduce the ambiguity regarding this unique clinical condition and also to shed light on various aspects of MIH in terms of management strategies.

Despite the clinical significance of MIH, little information is available on the perception of Indian dental surgeons regarding MIH in the country. There have been few prevalence studies in India.

The aim of this survey was to assess the experience of Indian dental surgeons regarding prevalence, clinical problems, and management of MIH with the broader aim of highlighting the need for prevalence studies for MIH in India. 


\section{MATERIALS AND METHODS}

The study was conducted between November 2017 and January 2018 after taking approval from ethical committee of Maulana Azad Institute of Dental Sciences, New Delhi, India.

A questionnaire was modeled on the ones by Weerheijm and Mejàre ${ }^{18}$ and Ghanim et $\mathrm{al}^{20}$ after obtaining permission from the authors. The clinical pictures used in the study were the same as those used by Weerheijm and Mejàre. ${ }^{18}$ There were a total of 15 multiple choice questions (Table 1 ). This questionnaire was then sent out to 1,500 Indian dental surgeons throughout the country including pediatric dentists using Google surveys. The data were compiled using MS Excel 2007 (Microsoft) and analyzed. Three reminders were sent at monthly intervals.

Table 1: Questionnaire

\begin{tabular}{lll}
\hline 1 & Educational qualification & Bachelor of dental surgery \\
& & Master of dental surgery \\
2 & Specialty & Pediatric dentist \\
& & Nonpediatric dentist
\end{tabular}

3 This question relates to the above Yes image. Do you encounter such No teeth in your practice? (image shown in the Google survey)

4 In your clinical work how often do you notice hypomineralized teeth?

Often in a week

Occasionally in a week

\section{Weekly \\ Monthly \\ Yearly}

5 Regarding the severity of defect, which of the following do you most frequently notice in your practice? (select all that apply)

White demarcation alone

Yellow/brown

demarcation alone

PEB

White + yellow/brown

demarcation

Yellow/brown

demarcation + PEB

White demarcation + PEB

All three together

Did not notice

6 In your practice do you feel the Yes incidence of hypomineralized No teeth has increased over the last 10 years, or in the period of your practice (if less than 10 years)?

7 Approximately what percentage Less than 5\% of patients do you observe $\quad 5-10 \%$ these teeth in?

$10-25 \%$

More than $25 \%$

8 How frequently do you notice More frequently this defect in the second primary Equal molar tooth in comparison to Less frequently first permanent molar?

9 Which factors do you think are involved in the etiology of $\mathrm{MIH}$ ? (select all that apply)

\section{Genetic}

Medications taken by mother during pregnancy Chronic medical condition affecting the mother during pregnancy

Acute medical condition affecting the mother during pregnancy

Fluorides
2 Which factors influence your choice of restorative material in such cases? (select all that apply)

13 Which material do you use to restore these teeth? (select all that apply)

14 Would you like to seek more information regarding tooth hypomineralization?

15 In which part/parts do you think Etiology

you need further information? Diagnosis (select all that apply)

Adhesion

Esthetics

Durability

Sensitivity

Others

GIC

Composite

Amalgam

Others

Yes

No
Environmental contaminants Chronic medical condition affecting the involved child Acute medical condition affecting the involved child

Medication taken by the involved child

Other

10 Do you think MIH is challenging Yes, very difficult Yes, somewhat difficult No

Diagnosis

Esthetics

Achieving adequate local anesthesia

Determining margins of affected tooth

Providing adequate restoration

Long-term success of restoration

Achieving patient comfort All of the above

Patient or parent preference

Remineralization potential

Personal experience

Research findings

High-fluoride GIC

Resin-modified GIC

Compomer

Flowable composite

Preformed crowns

Cast restorations

Management 


\section{RESULTS}

Of the 1,500 questionnaires mailed, 393 responses were received, with a response rate of $26.2 \%$. Twenty-eight questionnaires were partially completed. Responses were received from various clinicians as well as academicians and postgraduate students, which included 217 pediatric dentists and 176 nonpediatric dentists. It was observed that $96.3 \%$ of the total respondents encounter such teeth. Regarding the frequency, $43 \%$ of the pediatric dentists encounter such teeth often in a week, whereas overall $41.3 \%$ respondents reported that the frequency is monthly. The most commonly encountered clinical appearance was yellow/brown demarcation alone or associated with white demarcation and/or posteruptive breakdown (44\%), whereas only $3.56 \%$ (14 respondents) reported observing only posteruptive enamel breakdown (PEB) (Graph 1).

About $42 \%$ respondents reported that the incidence of hypomineralized teeth has increased. Another interesting finding was that there was a lot of variation among the respondents regarding the prevalence of such teeth in patients with $52 \%$ pediatric dentists reporting that 5 to $10 \%$ of their patients report with such teeth and $57 \%$ other respondents reporting it to be less than $5 \%$. There was general consensus among majority of respondents $(78.7 \%)$ that such condition is more frequently seen in permanent first molars rather than deciduous second molars. There was significant discrepancy among pediatric dentists and other respondents regarding the rise in incidence; 53\% pediatric dentists and $27 \%$ other respondents reported an increase in the incidence.

There was no agreement among the respondents regarding the etiology of $\mathrm{MIH}$ and $15 \%$ of the respondents attributed it to fluorides (Graph 2); 88.3\% respondents reported that they found MIH to be challenging to manage and most of them faced problems ranging from diagnosis, clinical management, and prognosis (Graph 3). Durability and esthetics were considered to be the major factors influencing choice of restorative material followed by adhesion and remineralization potential (Graph 4). There was a wide variation in the choice of restorative

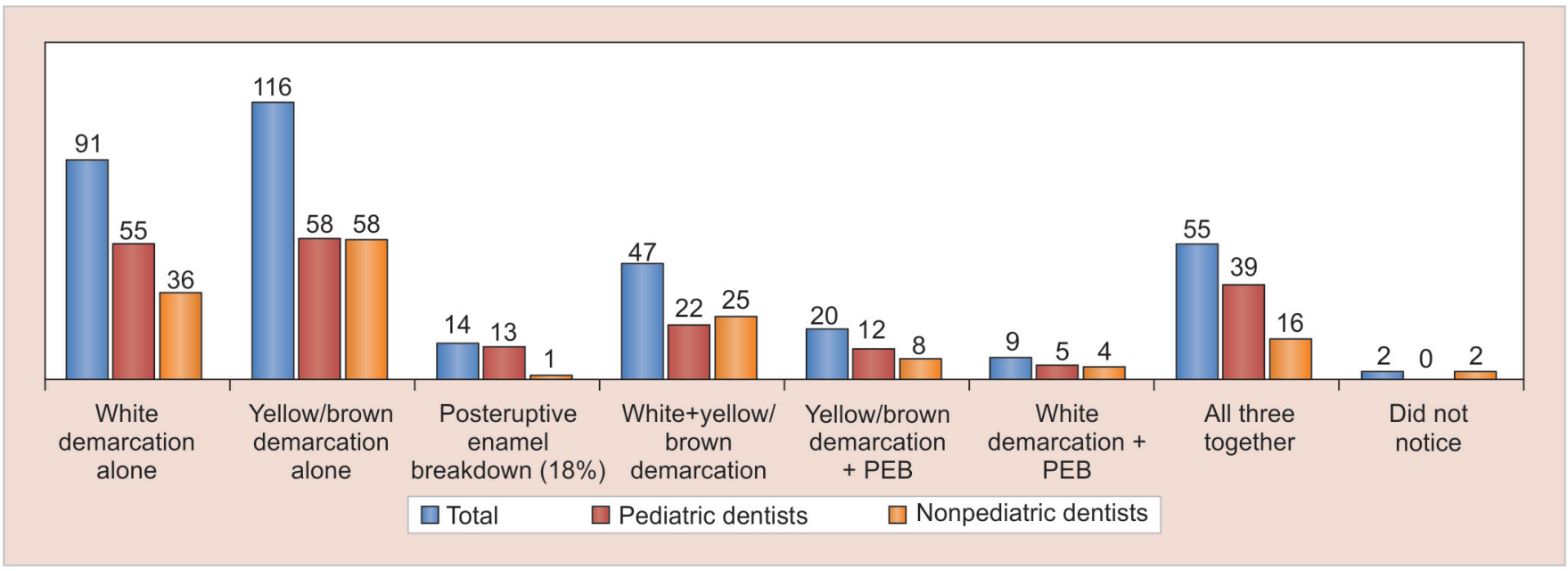

Graph 1: Clinical presentation observed by dental clinicians in $\mathrm{MIH}$

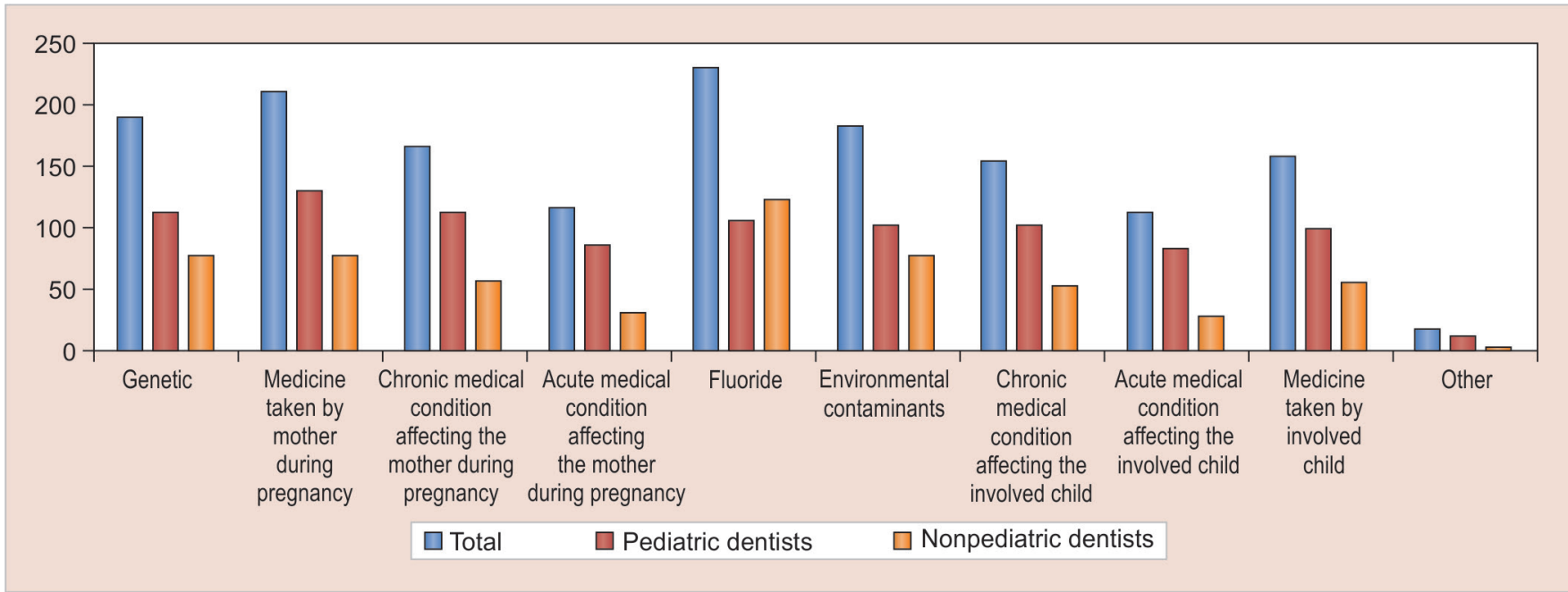

Graph 2: Distribution of responses regarding etiology of $\mathrm{MIH}$ 


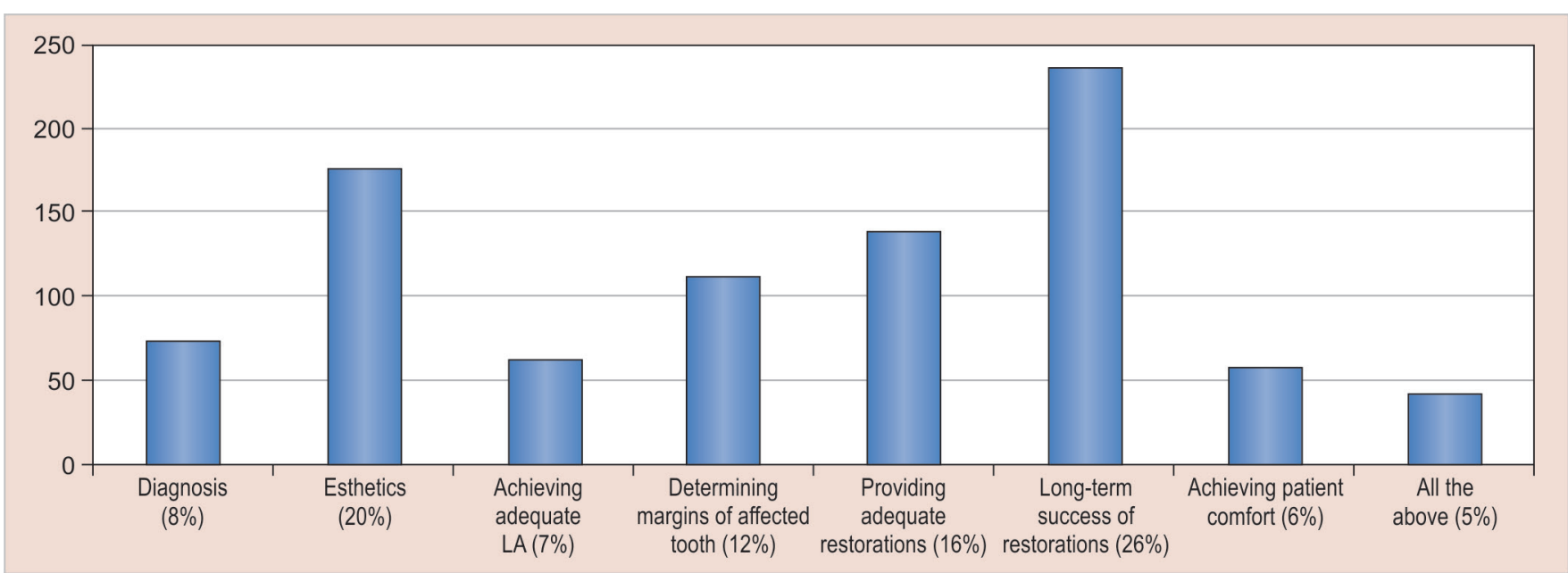

Graph 3: Challenges faced by dental clinicians regarding various aspects of $\mathrm{MIH}$

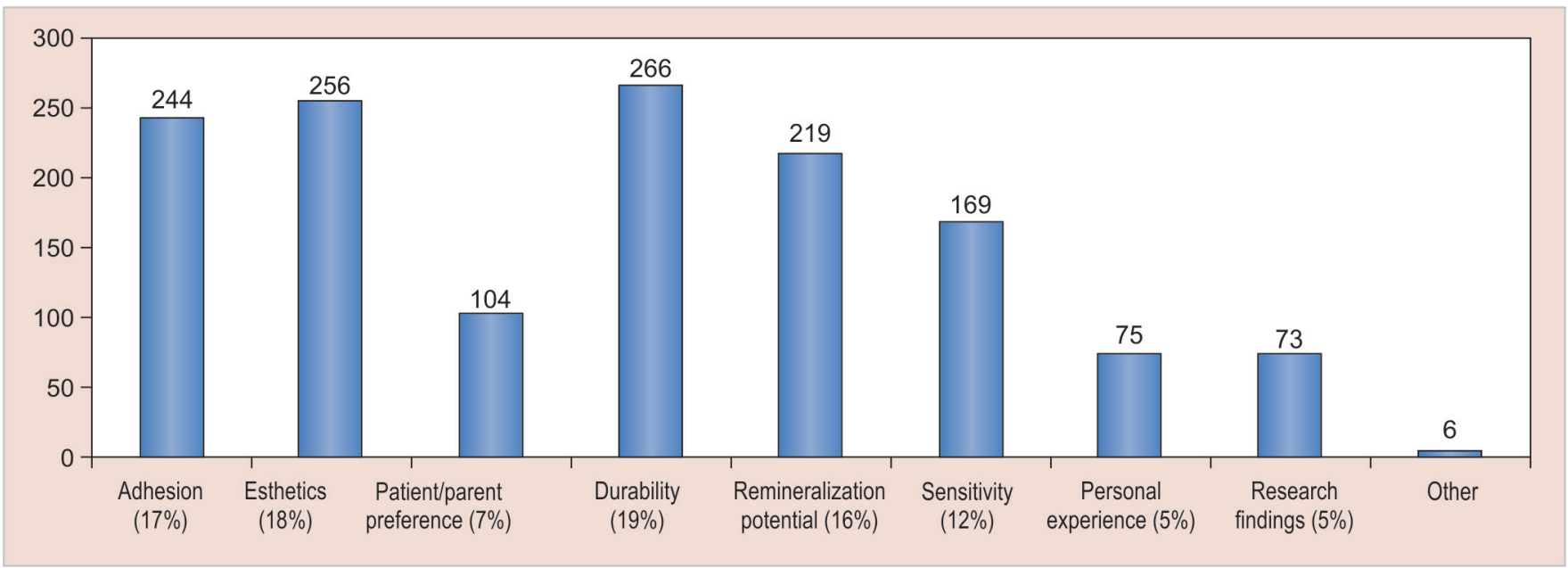

Graph 4: Factors under consideration in selection of restoration in teeth affected by MIH

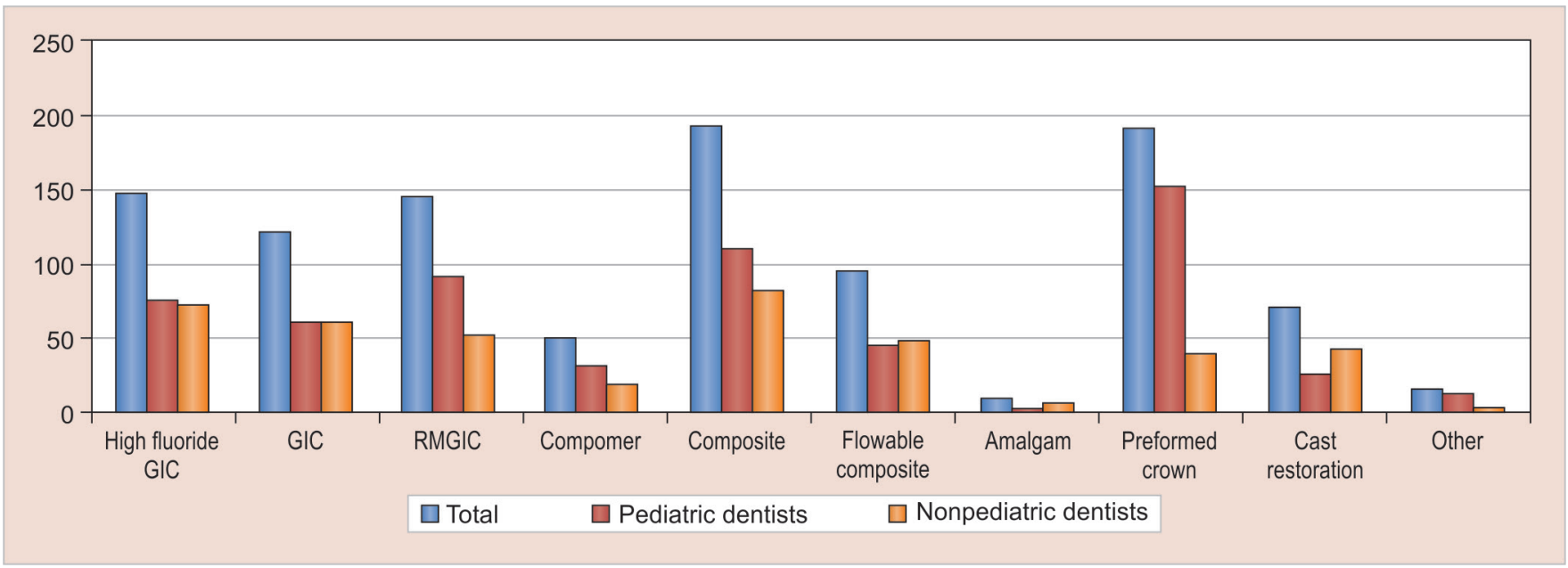

Graph 5: Restorative materials used for MIH

material in such teeth with pediatric dentists veering toward preformed crowns (Graph 5). About 88.5\% respondents felt that they require more information regarding management of MIH (Graph 6).

\section{DISCUSSION}

The epidemiology of dental caries and periodontal diseases has been widely studied in India. However, literature on $\mathrm{MIH}$ is sparse, although it is recognized 


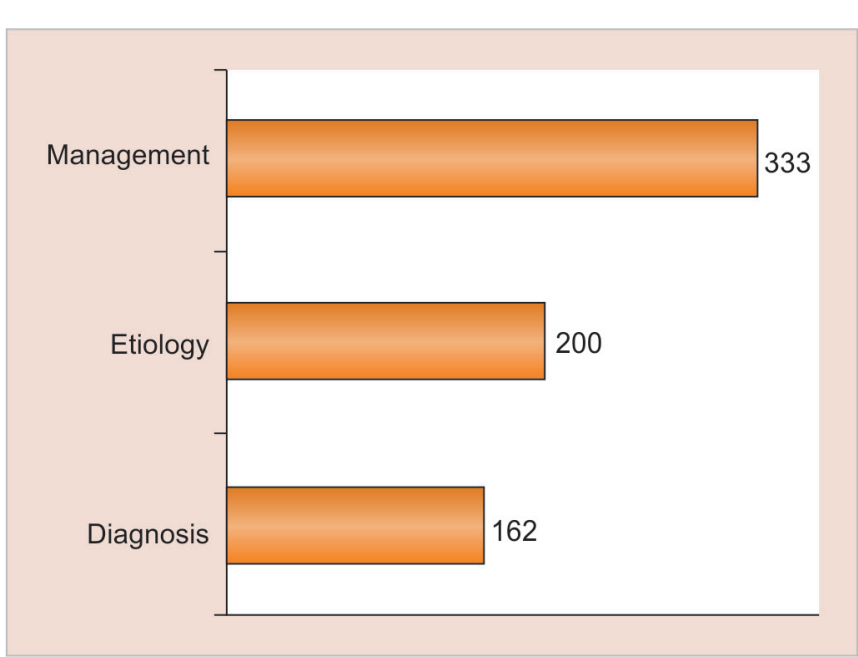

Graph 6: Areas perceived in which knowledge is required regarding $\mathrm{MIH}$

as a distinct clinical entity in India. This is probably the first study investigating perception of Indian dentists regarding this condition. The majority of participants in this study had encountered teeth affected by MIH, which is in agreement with the results of previous studies conducted in Europe, ${ }^{18}$ Australia and New Zealand, ${ }^{19}$ and Iraq. ${ }^{20}$

In the present study, it was observed that pediatric dentists encounter such teeth more frequently than other dental practitioners. This may be attributed to the fact that pediatric dentists encounter children exclusively as compared with any other dental practitioner. Also adult patients may often have had restoration of such teeth or the affected tooth/teeth might have been lost and no longer exhibit signs of $\mathrm{MIH}$ when reporting to the dentist thus leading to the lower prevalence reported. Another factor responsible for such a skewed response might be that other practitioners often lack knowledge about this condition so they might be missing out on the presentation. The fact holds true that eyes see only what the mind knows. There was a varied response regarding prevalence of $\mathrm{MIH}$ with $52 \%$ pediatric dentists reporting the prevalence to be 5 to $10 \%$, while most of others $(57 \%)$ reporting it to be less than $5 \%$. This disparity could be attributed to various reasons, such as different birth cohorts or different ages of the children at examination. It could also reflect real differences between regions. There may have been differences in criteria for examination of these teeth. This emphasizes the need to perform a survey of this condition with calibrated examiners. Moreover, due to varied presentation depending upon the extent of involvement, age of patient at the time of diagnosis, and degree of damage, it becomes difficult to categorize MIH. The most common clinical manifestation encountered by the participants in our study was yellow / brown demarcation either alone or in combination with others (44\%) and the least commonly seen was PEB (18\%). This might be explained by the fact that yellow / brown enamel opacities have shown to be more porous than lighter opacities. ${ }^{21}$ A correlation between hardness values, mineral density, and the color of the hypomineralized enamel has been shown, with yellow/brown opacities being softer than white. $^{22,23}$ This leads to early breakdown and associated symptoms causing the affected patients to seek treatment. Yellow/brown opacities are easily distinguishable from fluorosis and white spot lesions due to caries as compared with other clinical manifestations of MIH leading to early differentiation. Moreover, PEB may often go unrecognized. Posteruptive enamel breakdown most often occurs shortly after eruption, when the affected tooth is under occlusal load. ${ }^{24}$ This may be mistaken as dental caries by the untrained eye.

Scientists and clinicians are still trying to establish the exact etiological factors for MIH. There is still plenty of ambiguity regarding the etiology of MIH. Several factors have been proposed but there is no consensus as all the studies have been retrospective in nature. This ambiguity is reflected in the response of the participants as well. There is a need to have experimental, animal, and prospective cohort studies on MIH to establish the exact etiology.

Molar incisor hypomineralization is a unique condition associated with difficulty in diagnosis due to lack of a uniform assessment and identification criteria. Patients affected with MIH are more likely to have behavior management problems as well as dental fear and anxiety due to repeated treatments and hypersensitivity. ${ }^{8}$ This is reflected in the responses of the present survey.

There is frequent breakdown of restorations due to the porous nature of enamel in $\mathrm{MIH}$, thus making durability of the restoration a critical factor as evidenced by the participant's responses [etching and bonding difficulties, adhesion failures with glass ionomer cements (GICs) due to improper crystal lattice]. Another interesting finding of this survey was that pediatric dentists preferred preformed crowns as the restoration of choice as compared with other dental surgeons. This might be attributed to familiarity with use of preformed crowns among the former (multisurface involvement, superadded with dental decay).

A large majority of participants expressed an interest in obtaining further information about $\mathrm{MIH}$, thus highlighting that there is awareness regarding this condition among Indian dental surgeons.

Limitations of the study:

- There is a low response rate of mailed questionnaires due to lack of personal contact. There is no opportunity to cross examine the responses. 


\section{CONCLUSION}

Molar incisor hypomineralization is a common condition encountered by dental professionals with no apparent consensus regarding the anticipated prevalence, severity, and etiology of this condition. Thus, there is need for conducting research in various aspects of $\mathrm{MIH}$.

\section{What This Article Adds}

Molar incisor hypomineralization is commonly encountered by Indian dental clinicians and is considered to be a common clinical problem.

\section{Why This Article is Important for Pediatric Dentists}

- The results of this survey will raise awareness about this unique and difficult to manage clinical condition.

- This survey might motivate others to look into research on various aspects of $\mathrm{MIH}$.

\section{ACKNOWLEDGMENTS}

Authors would like to thank Drs KL Weerheijm, I Mejare, Aghareed Ghanim, Michael Morgan, Rodrigo Marino, David Manton, and Denise Bailey for allowing them to use their questionnaire and photographs for conducting the present study.

\section{REFERENCES}

1. Koch G, Hallonsten AL, Ludvigsson N, Hansson BO, Holst A, Ullbro C. Epidemiologic study of idiopathic enamel hypomineralisation in permanent teeth of Swedish children. Community Dent Oral Epidemiol 1987 Oct;15(5):279-285.

2. Jalevik B, Noren JG. Enamel hypomineralization of permanent first molars: a morphological study and survey of possible aetiological factors. Int J Paediatr Dent 2000 Dec;10(4):278-289.

3. Fearne J, Anderson P, Davis GR. A3D X-ray microscopic study of the extent of variations in enamel density in first permanent molars with idiopathic enamel hypomineralization. Br Dent J 2004 May;196(10):634-638.

4. Leppaniemi A, Lukinmaa PL, Alaluusua S. Nonfluoride hypomineralizations in the permanent first molars and their impact on the treatment need. Caries Res 2001 Jan-Feb;35(1):36-40.

5. van Amerongen WE, Kreulen CM. Cheese molars: a pilot study of the etiology of hypocalcifications in first permanent molars. J Dent Child 1995 Jul-Aug;62(4):266-269.

6. Weerheijm KL, Groen HJ, Beentjes VE, Poorterman JH. Prevalence of cheese molars in eleven-year-old Dutch children. ASDC J Dent Child 2001 Jul-Aug;68(4):259-262.

7. Weerheijm KL, Jälevik B, Alaluusua S. Molar-incisor hypomineralisation. Caries Res 2001 Sep-Oct;35(5):390-391.

8. Jalevik B, Klingberg GA. Dental treatment, dental fear and behavior management problems in children with severe enamel hypo mineralization of their permanent first molars. Int J Paediatr Dent 2002 Jan;12(1):24-32.

9. William V, Messer LB, Burrow MF. Molar incisor hypomineralization: review and recommendations for clinical management. Pediatr Dent 2006 May-Jun;28(3):224-232.

10. Kodaka T, Debari K, Kuroiwa M. Mineral content of the innermost enamel in erupted human teeth. J Electron Microsc 1991 Feb;40(1):19-23.

11. Kodaka T, Debari K, Yamada M, Kuroiwa M. Correlation between micro-hardness and mineral content in sound human enamel (short communication). Caries Res 1992;26(2):139-141.

12. Fearne J, Anderson P, Davis GR. 3D X-ray microscopic study of the extent of variations in enamel density in first permanent molars with idiopathic enamel hypomineralisation. Br Dent J 2004 May;196(10):634-638.

13. Jälevik B, Odelius H, Dietz W, Norén J. Secondary ion mass spectrometry and X-ray microanalysis of hypomineralized enamel in human permanent first molars. Arch Oral Biol 2001 Mar;46(3):239-247.

14. Xie ZH, Mahoney EK, Kilpatrick NM, Swain MV, Hoffman M. On the structure-property relationship of sound and hypomineralized enamel. Acta Biomater 2007 Nov;3(6):865-872.

15. Cho SY, Ki Y, Chu V. Molar incisor hypomineralization in Hong Kong Chinese children. Int J Paediatr Dent 2008 Sep;18(5):348-352.

16. Wogelius $\mathrm{P}$, Haubek D, Poulsen S. Prevalence and distribution of demarcated opacities in permanent 1st molars and incisors in 6 to 8-year-old Danish children. Acta Odontol Scand 2008 Feb;66(1):58-64.

17. Soviero V, Haubek D, Trindade C, Matta T, Poulsen S. Prevalence and distribution of demarcated opacities and their squeals in permanent first molars and incisor in 7 to 13-yearold Brazilian children. Acta Odontol Scand 2009;67(3):170-175.

18. Weerheijm KL, Mejàre I. Molar incisor hypomineralization: a questionnaire inventory of its occurrence in member countries of the European Academy of Paediatric Dentistry (EAPD). Int J Paediatr Dent 2003 Nov;13(6):411-416.

19. Crombie FA, Manton DJ, Weerheijm KL, Kilpatrick NM. Molar incisor hypomineralization: a survey of members of the Australian and New Zealand Society of Paediatric Dentistry. Aust Dent J 2008 Jun;53(2):160-166.

20. Ghanim A, Morgan M, Marino R, Manton D, Bailey D. Perception of molar-incisor hypomineralisation (MIH) by Iraqi Dental Academics. Int J Paediatr Dent 2011 Jul;21(4):261-270.

21. Da Costa-Silva CM, Ambrosano GM, Jeremias F, De Souza JF, Mialhe FL. Increase in severity of molar-incisor hypomineralization and its relationship with the colour of enamel opacity: a prospective cohort study. Int J Paediatr Dent 2011 Sep;21(5):333-341.

22. Suckling GW, Nelson DG, Patel MJ. Macroscopic and scanning electron microscopic appearance and hardness values of developmental defects in human permanent tooth enamel. Adv Dent Res 1989 Sep;3(2):219-233.

23. Farah R, Drummond B, Swain M, Williams S. Linking the clinical presentation of molar-incisor hypomineralisation to its mineral density. Int J Paediatr Dent 2010 Sep;20(5):353-360.

24. Weerheijm KL. Molar-incisor-hypomineralisation (MIH). Eur J Paediatr Dent 2003 Sep;4(3):115-120. 